\section{THE VALUE OF $X$ RAYS IN MEDICINE AND SURGERY.}

By NATHAN RAW, M.D., B S., L.S.Sc. DuRH., MEDICAL SLPELINTENDENT AND PATHOLOGIST, DUNDEK RUYAL IYFIRMARY.

THE accompanying illustration shows very many points of great interest to the anatomist, physician, and surgeon. Briefly described, it is a skiagraph (originally life-size and reduced to one-third) of a boy aged six years who died in the hospital from meningitis. His father expressed a wish that he should be examined by means of the "new light," which request was complied with. In order to test whether or not foreign bodies placed in the body could be accurately located and recognised I inserted a brass watch-key as far as possible into the right bronchus through an opening in the trachea. I also inserted a small, leaden toy pistol (as being an object easily recognisable and also very opaque to the rays) into the cxcum and carefully closed the openings. I then laid the body upon a negative 24 in. by $18 \mathrm{in}$. in size carefully folded in several layers of brown paper and placed the focus tube exactly in the centre above at a distance of $20 \mathrm{in}$. The platinum anode was directed obliquely and almost parallel to the surface of the chest. The exposure given was fifty minutes, the current being turned off every five minutes to cool the platinum and also to warm the tube with a spirit lamp. The negative was developed with amidol solution and a bromide print was taken with an exposure of thirty seconds. The points of interest are the following.

The fortign bodies. - The watch-key being of greater opacity is distinctly seen pointing downwards and ontwards, a little to the right of the middle line, and opposite the third and fourth ribs apparently (it must be remembered that this print is a negative and not a positive) ; part of it is lying directly in front of the vertebral column so that its outline is actually shown tbrough the vertebræ. The toy pistol is most distinctly seen over the cæcal region, and so well is it delineated that the trigger and other parts can be actually made out.

The outlines of the viscera.-These I consider are well delineated. The lungs are seen to be quite transparent to the $\mathrm{x}$ rays; the upper limits in the large picture are not above the clavicle, whilst the lower boundaries on the diaphragm are well seen. The outline of the heart is shown rather larger than in the normal, but this was due to the pericardium being distended with fluid. The narrowing of the pericardial sac is well seen. The diaphragm is shown with the liver outlined, especially the right lobe. The vertebral column is actually seen showing through the liver. The kidneys and spleen cannot be definitely made out on the original picture.

The skeleton.-The chief interest in the bones is of course the fact of their being in the developmental stage. The vertebral column is seen in its entirety, a considerable space being seen between the bodies of the lumbar vertebræ. The shadows of the ribs forming the posterior wall of the thorax are, of course, better seen than those in front, whilst the out line of the sternum is absent. This is due to the fact that the posterior wall was next the plate. The clavicies are seen with the scapular end not shown being cartilaginous. The scapula and the thicker parts, including the glenoid cavity, are well seen. The coracoid process, the nucleus of which appears at the first year, is prominent, whilst the acromion, the nuclei of which do not appear until the fourteenth year, is not seen. The spine of the scapula is shown as a dark shadow through the body of the scapula itself. The humerus is very interesting. The nuclei of the head and tuberosities have united to form an epiphysis, which is not united to the shaft until the twentieth year. In the lowe end the epicondyle of Chaussier is well seen, which unites with the shaft at the sixteenth year. In the radius the nucleus of the head, which only appears at the fifth or sixth year, is just seen whilst the nucleus of the carpal end, which appears at the end of the second year, is prominent as a separate epiphysis. The nucleus of the carpal extremity of the ulna is just seen as it appears at the fifth year. The carpal bones are very interesting. The os magnum (first year), unciform (second year), cuneiform (third year) trapezium and semilunar (fifth year), and scaphoid just appearing (sixth year) are well seen. The trapezoid (seventb year) bas not yet appeared. The left arm is pronated and the point where the radius crosses the ulna is seen to be high. up The pelvic bones are not well seen, but the femora are distinct.

In another large skiagraph I made an attempt to exactly delineate the ontlines of the viscera as follows. I carefully opened the chest and abdomen of an adult male and exposed all the solid viscera. I then carefully placed a piece of thick copper wire exactly round the edges of the heart, lungs, liver, spleen, and kidneys, that of the heart encircling also the aorta with a bend corresponding to the aortic valve. The wire encircling the kidneys was continued down the ureters. I also placed four calculi in the gall-bladder and calculi in the renal cortex, in the pelvis, and also in the ureter, and carefully closed the cavities, replacing the ribs exactly. With an exposure of sixty minutes a good negative was obtained which showed all the points desired very well, the calculi being especially clear. Owing to the vibration of the lamp there was in places a double line. I hope to be able to do better plates with further experience on this point.

The current used was from our own installation (ten rolts twelve ampères). An induction coil by Harvey and Peake of London and focus tubes by Reynolds and Branson of Leeds were used. I must also express my indebtedness to Mr. Ross, our dispenser, and also to Messis. Valentine and Son, photographers, for the prints.

Dundee.

\section{ON LATENT AND TRANSIENT PERI- CARDIAL EFFUSION.}

BY WTLLIAM EWART. M.D. CANTAB., F.R.C.P.LUXid. PAYSTCIAN TO ST. GEORGE'S HOSPITAL AND TO 'THE LELGRAYE HOSPITAL FOR CHILDREN.

Professor Clifford Allbuta ${ }^{1}$ describes under the heading of Quiet Pleurisy with Effusion a familiar group of cases in which effusion takes place by degrees and without any pain or initial severity of symptoms, the patient ultimately seeking advice in connexion with anrmia and incapacity for exertion at a time when the fluid has already accumulated to a considerable extent. That pericarditis also occurs in a latent way is a fact anatomically dernonstrated by the agglutinations, the bands of adhesion, the thickenings, and the fibrinous deposits found after death in the pericardium of those in whose history there is no record of pericarditis. Some fluid is probably effused in all cases of pericarditis, though in many of these milder or limited attacks its amount must be small. Yet, both as regards origin and subsequent behaviour, the history of effusions differs in the two serous sacs. At any rate, I do not at present possess a sufficient series of clinical cases in point to construct a group of quiet pericarditic effusions absolutely analogous to tinat of the "quiet pleurisies," though other observers may be provided with that material. This communication does not therefore venture bey ond the recognition of latent pericardial effusions, irrespectively of their mode of origin, which doubtiess in some cases is inflammatory. It is written in the belief, based upon repeated clinical observations, that pericardial $\epsilon$ fiusion is less infrequent than is sometimes thought, and that it may originate, run through a short course, and disappear entirely unsuspected. Looking back over clinical studies of the last few years I call to mind several cases in which the effusion had not been detected at first, and might readily have passed unrecorded but for the chance of a renewed examination of the chest having been made at an opportune moment. The three following cases, admitted into St. George's Hospital and still under my treatment at the time of writing. are striking illustrations of their kind. They were specially instructive as affording an opportunity of following the process from beginning to end, of accurately studying its stages by percussion, and of keeping exact tracings of the surface markings obtained during and after the period of efinsion.

CASE 1. Nephritis - A man aged for ty years, strong and healthy in aspect, but slightly pallid, applied for admission to 
Supplement to The Lancet, Noz'. 21 st, 1896.

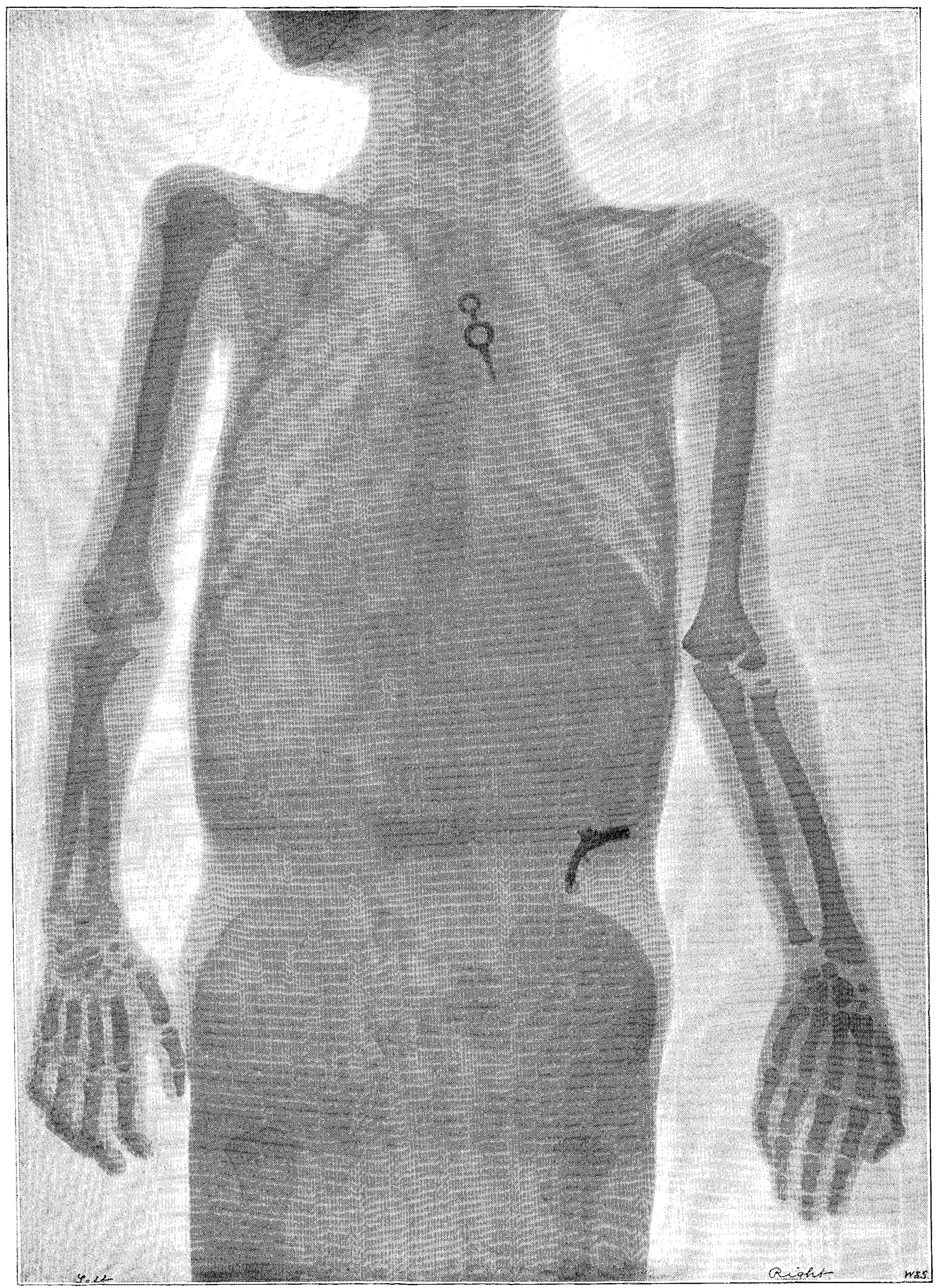

SKIAGRAPH OF BUY, Aged 6. One-Third Life Size. By NATHAN RAW, M.D.

Showing Watch Key inserted into Right Bronchus, also Lead Toy Pistol inserted into Cæcum. Showing outlines of Heart, Lungs and Liver, and Epiphyses of Bones. 

hospital on account of slight anasarca of a fortnight's standing and for albuminuria which had been preceded seven or eight weeks previously by a slight purpuric attack in the arms and legs. There being no cardiac murmur and no complaint of any chest pain or severe dyspnœa it was suggested at first that he should call again, the hospital being very full. But a rapid percussion of the cardiac area revealed the unmistakeable signs of pericardial effusion and he was sent into the ward, where a careful examination was made and a tracing taken of his cardiac dulness. The latter presented the characteristic angular otitline at both anterior bases, the left angle of dnlness extending an inch and a half beyond the apex beat, which was felt just within the nipple line at the normal hepatic level. External to the præcordial dulness fine crepitations were heard on deep anspiration, which were probably due to the re-inflation of compressed lobules. The absolute dulness was extensive and included the sternum. The characteristic posterior basic patch of dulness was well marked. The next day the same physical signs were verified, though the area of dulness was rather less. On the fourth day, after free purgation and some diuresis, which lessened the oedema and made the patient feel much brighter, the cardiac area of dulness was found to be absolutely normal, the absolute cardiac dulness of average size, the 11 ght angle of dulness gone, the left angle terminating at the apex beat, and the posterior basic patch of dulness absent. The physical signs described did not return in spite of persistent albuminuria and of an attack of hæmaturia a frigore after going into the open on a cold day. After a furtber stay of three weeks in the hospital, whilst I was verifying their absence, I discovered the signs of right pleural effusion. The dulness rose to the level of the fifth dorsal spine, was continued forward at a lower level, occupying the interval between the nipple and the liver dulness, the latter being plainly differentiated as faintly resonant relatively to the duller fluid. The exact date of this pleural effusion could not be determined, the patient not having experienced any discomfort whatever. Throughout this case no pericardial fxiction and no other sign or symptom of pericarditis were discovered.

CASE 2 Valvular disease.-A man aged forty-five years was admitted to hospital a few days after the preceding case for dyspnoea of eight months' standing, with frequent giddiness and fainting fits (three or four in a week on moderate exertion for the last four months), the more recent symptoms being insomnia, several slight attacks of hæmoptysis, and for a week prior to admission considerable wedema of the legs. He had had rheumatic fever fifteen years ago, but had been in fair health until last Christmas, the date of his first fainting fit. On admission his aspect was fairly strong. No anasarca remained and the liver was only moderately enlarged. The area of cardiac dulness was increased and four murmurs were heard. The aortic second sound was inaudible to the right of the sternum; here a double aortic murmur could be traced, though this was louder to the left. Just above the apex was heard a distant diastolic rumble and at the apex and over the heart in general a loud systolic murmur. The medical registrar, Dr. Russell Wells, also found some evidence of tuid at the right posterior region of the chest, where the breath sounds and voice sounds were deficient, and a few râles could also be heard. This dulness rose to the level of the scapular angle, and some dulness was also noted at the extreme left posterior base. On the fifth day he was allowed to get up for an hour and subsequently for longer periods. Six days after bis first getting up, noticing that he was not looking well, I made a thorough examination. When he was made to lie down for this purpose he became distinctly cyanosed, with turgid jugulars and obvious signs of venous embarrassment. The right chest was found to contain a considerable amount of fluid; but in addition there was evidence of somewhat considerable effusion within the pericardium. The dulness, extonding across from the border of the right nipple to one inch and a half beyond the left nipple and to about half an inch beyond the apex beat, which occupied the normal hepatic level, was distinctly angular at the right anterior base; the absolute dulness extended to the right well beyond the middle line of the sternum, and to the left as far as the centre of the nipple. A well-marked posterior basic patch of dulness was made out. A tracing of these outlines was made at the time. The patient was kept in bed and treated with Baillie's pill and other diuretics. A subsequent examination made four days later and likewise followed by an accurate tracing showed complete restoration of the normal outline of cardiac dulness. The absolute dulness was still rather large, but it extended only slightly beyond the middle line, and its left boundary was an inch and a half internal to the centre of the left nipple, and hardly reached as far as the apex beat. The posterior basic dulness was almost absent. The right pleural dulness had considerably diminished. A third examination four days after the last gave complete resonance over the previously dull dorsal patch and an absence of the signs of effusion in the right chest. Throughout this case no pericardial friction was heard, and the patient did not complain of any chest pain or discomfort.

CASE 3 Aloute rheumatism.-A man aged twenty years was admitted to hospital on Sept. 15th, 1896, after six days spent in bed, with acutely swollen joints and stiffness. He had not been treated medically. The aspect was unusually drawn and respiration was rather rapid, distantly suggesting the possibility of pericarditis; but besides the discomfort and awkwardness of breathing arising from pain in the joints there was neither thoracic distress nor. conscions dyspnœea. The examination of the heart reported on Sept. 16th gave "no friction, a booming first sound, and a faint systolic murmur a the a pex." Meanwhile a careful percussion had been made by me on Sept. 15th, and this at once detected the characteristio outline of pericardial effusion at the right thoracic base, whilst at the left base the dulness extended beyond the seat of the apex beat. The patient's condition precluded any examination of the back for the presence of a posterior basic cull patch. An accurate tracing was preserved. Next day, under salicylates, the arthritic pain was greatly relieved, and on examination the outline of cardiac dulness had returned almost to the normal. On the third day no trace remained of the effusion and percussion of the back was perfectly normal. A tracing was taken of the normal præcordial dulness, and this showed, as might have been expected, a reduction of the originally slightly enlarged area of absoIute dulness. A relapse of the effusion was carefully looked for from day to day, but none occurred. The rheumatic and probably inflammatory origin of the effusion and the rapidity of its re-absorption under treatment are points of interest. This case supports the correctness of another similar observation much anterior to this, where a considerable but evanescent pericardial effusion was diagnosed in a case of acute rheumatism, with subsequent hyperpyrexia and death, the usual symptoms of pericarditis not having been noticed. In the present case there was no obvious evidence of any pericardial complication, and the effusion would certainly have escaped notice but for a strict percussion By a singular and significant coincidence the three cases related were under treatment in the wards simultaneously.

The fact that pericardial effusions may be overlooked, even when of considerable extent and even when the severity of the symptoms is such as to call attention to the chest, has been dwelt upon elsewhere. ${ }^{2}$ But we are now dealing with cases of moderate effusion in which our suspicions are not aroused by any symptoms and which a superficial examination would probably fail to identify. That such cases occur we have proof in the two instances narrated and in others. The inference that they are perhaps not rare is based upon the almost accidental way in which the condition was noticed and upon the fact that it was not at first recognised by a less searching examination. The latency of pericardial effusions is favoured by the rapidity with which they may take place as well as by their often early re-absorption. The suddenness with which fluid is sometimess effused into the pleural cavities, and often also into that of the pericardium, as a final vital act is constantly attested by the house physicians at our hospitals. All three cavities may be so full as to make it obvious that the condition could not have subsisted for any long period prior to death. Without equalling this rapidity smaller pericardial effusions occurring as mere complications may probably take place within a very short time, and, owing to the well-known tolerance of the heart for lateral pressures, without setting up any major symptoms, especially in bed-ridden patients. An early examination with negative result need not, therefore, be conclusive as to the subsequent freedom of the patient from this complication during a series of days elapsing without any searching examination of the chest being made. Our chances of entirely overlooking these effusions are much increased by the comparative rapidity of

2 See Brit Med. Jour. March 2lst, 1896. Practical Aids to the Diagnosis of Perieardial Effusion in Connesion with the Question as to Surgical Treatment. 
their re-absorption. Stagnation of the serous fluid, which is the rule in the pleura, is the exception in the pericardium. Even in acute pericarditis the cluration of the stage of effusion is measured by days. This difference may be due to the difference in size of the serous cavities, but possibly also to various other circumstances. For instance, in the case of the pleura the respiratory movements of the side affected coming to a standstill, the elasticity of the lung acts somewhat after the fashion of an aspirating pump, terding to keep the fluid within the pleural sac, whilst no mechanical force is brought to bear in the direction of its relief. Moreover, the flaid gains access to the deep recesses of the pleura, which are commonly unoccupied by lung and from which it would be by no means easy to dislodge it. Pericardial effusion, on the otber hand, does not suspend the play of respiration, and the influence, which may be beneficial, of the passive movement thus applied externally to the sac is maintained. Moreover, within the sac the fluid cannot get away from the heart and is kept by it in perpetual motion this, again, may be a fuvouring circumstance. Lastly, the heart is neither compressible by the fluid nor capable of exercising upon it any permanent aspiration.

The diagnosis of these cases presents no real difficulty, and, with sufficient auscultatory skill and a thorough familiarity with the elements of cardiac and pericardial percussion, it can be made rapidly and with certainty. The method of diagnosis of pericardial effusion having been already described at some length $^{3}$ it will suffice to lay stress on one only of the most telling physical signs, which is also that obtained most readily and with least disturbance to the patient-viz., the alteration in the outline of the normal cardiac dulness at the anterior base of the thorax. This method, howerer, can only possess any value in the hands of those who are competent to delineate with strict accuracy the actual shape of the heart as projected on the anterior chest wall, and not merely the comparatively unimportant, because inconslusive, outline of the absolute cardiac dulness. The whole point turns upon the alteration of the convexity of the dulness due to the right auric'e (this convexity extending downwards from the right fourth interspace to the infra-sternal notch) into a straight line passing outivards and downwards and forming an angle with the "hepatic line of absclute dulness." This angle of dulness inslades, as long ago pointed out by Rotch, the right fifth interspace; but inasmuch as displacement of the heart or considerable enlargement of its right side sometimes renders this interspace clull, it is the altered outline of the dulness rather than the fact of the fifth right intercostal space becoming dull which is the characteristic sign of pericardial effusion.

In the dizeases in which it is apt to occur we cannot afford to neglect a complication which may be franght with the gravest consequences. At first the character of the process may be uncertain. If the effusion should prove to be, not temporary, but of the progressive and permanent kind, a distinct advantage would be gained by its discovery at an earlier date than sornetimes happens. On the other hand, our recognition of the efiusions now under consideration, which are of epsemeral duration and not of severe type, would modify in a favourable direction our estimate of the prognosis of pericas dial effusions in general. Our medicinal treatment, directed to the speedy cure of the condition if mild, and to its timely control if it should be the early stage of the severe form, would in both cases be applied to the best advantage; and if any operative measures should become ultimately necessary they might be planned without hurry and without delay.

From the foregoing observations and remarks the following conclusions may be drawn:-1. Effusions may occur in the pericardium independently of acute pericarditis, under the inflaence of rheumatism, of carciac affections, of Bright's disease, \&s. 2 If of moderate size they may be capable of rapid re-absorption; axd in that case, not attracting attention either by the puinful symptoms of pericarditis or by the pressure symptoms of fluid, they may often run their course unobserved. 3 . As in the case of the analogous pleural effusions they may be dependent upon a sub-acute inflammatory process. More often they are probably passive or mechanically induced. 4. Rest and diet and the administration of cathartics, of diaphoretics, and of diuretics are the only treatment needed in the average case. In severe cases, which are usually those of advanced kidney disease, the effusion as it steadily increases kecomes obvious, and paracentesis may be necessary. 5. The most important practical conclusion is that our physical eximination should be accurate and searching, and that in all cascs of enlarged procordial dalness the simple tests for the presence of pericardial thaid which have been describech should be thoroughly applied. Curzon-street, $\mathrm{W}$.

\section{OVARIOTOMY IN COUNTRY PRACTICE.}

\section{BY F. SIDNEY GRAMSHAW, M.D. ST. AND.}

THE following cases may perbaps be worthy of record, as they were undertaken in a country village where the circum. stances of the patients rendered it impossible to obtain the services of an experienced operator and the nursing had to depend upon the exertions of one nurse who had never had charge of an ovatiotomy case before.

CASE 1.-The patient was a married woman aged thirtyone years, who had had two children, the younger of whom was aged eight years. Up to this time-i.e., the birth of her last child-she was a robust, healtby woman. When this child was four years of age I attended the mother in a slight attack of peritonitis resulting from a severe strain received in jumping over a ditch while running away from a cow. She told me she had not menstruated regularly since her confinement; under the usual routine treatment she soon recovered, and I saw her no more professionally until July, 1890, when she sent for me to determine the cause of her rapidly increasing size. She presented the appearance of a pregnant woman at fall term, but she had not menstruated for three years and bad perceived no foetal morements. I had her put to bed and scon satisfied myself as to the nature of her condition. The enlargement was perfectly symm metrical, she measured thirty-nine inches at the umbilicus, the whole abdomen was dull to percussion, the fluctuation was well marked, and there was no resonance in either flank, whatever ber position. The tongue was foul, the bowels were constipated, and the urine was scanty and highly coloured;'she also presented the well-known appearance of facies ovariana. I kept her under observation and found, by frequent and careful measurements, that she steadily increased in size, the increase being accompanied ky constant distressing pain in the back and great discomfort from the disiension. By the last week in August her girth at the umbilicus had increased to fifty inches, and having also considerable odema of the thighs she was quite unable to move about. The patient and her friends were told of the necessity for operation and of the usual poor results from any palliative treatment; but as they seemed to shrink from the more formidable proceeding I reluctantly agreed to tap the tumour, which I did with due antiseptic precautions. When fifteen pints bad been drawn oft, the enlargement being apparently diminished by one half, the flow stopped suddenly. The next day she was much better and commenced to menstruate, the discharge being normal in character and lasting four days. The only good result which followed the tapping was an entire freedom from the pains which had tormerly made her life a burden, but she began almost immediately to again increase in size. Warned by her expesience of the utter futility of tapping she expressed at strong desire to undergo the operanion of ovariotomy and earnestly requested me to perform it myself with as little delay as possible. I ordered her a nutritious diet, gave her an iron tonic, and regulated her stornach and bowels. Owing to the insanitary, small, and crowded condition of her own house I refused to operite unless a more suitable place could be found. This difliculty was overcome by my having a large, empty, and comcaratively new house lent me for the purpose in the village. I selected for the operation a ground.floor room $17 \mathrm{f}$. by $15 \mathrm{ft}$. by $11 \mathrm{ft}$. in dimensions. The ceiling was well washed with carbolised water, the walls were first rubbed with bread and then with a cloth damped in a like solution, and the floor having been scrubbed three times with hot water avd soap, I cansed is and the woodwork of the room to be thoroughly washed five times with a perchloride of mercury solution ( 1 in 1000). On Nov. 11th, the day before the operation, two large steam sprays were at work all the afternoon dispersing a 1 in 30 